\title{
Two Modes of Change of the Distribution of Rain*
}

\author{
Angeline G. Pendergrass And Dennis L. Hartmann \\ Department of Atmospheric Sciences, University of Washington, Seattle, Washington
}

(Manuscript received 28 February 2014, in final form 23 July 2014)

\begin{abstract}
The frequency and intensity of rainfall determine its character and may change with climate. A methodology for characterizing the frequency and amount of rainfall as functions of the rain rate is developed. Two modes of response are defined, one in which the distribution of rainfall increases in equal fraction at all rain rates and one in which the rainfall shifts to higher or lower rain rates without a change in mean rainfall.

This description of change is applied to the tropical distribution of daily rainfall over ENSO phases in models and observations. The description fits observations and most models well, although some models also have an extreme mode in which the frequency increases at extremely high rain rates. The multimodel mean from phase 5 of the Coupled Model Intercomparison Project (CMIP5) agrees with observations in showing a very large shift of $14 \%-15 \% \mathrm{~K}^{-1}$, indicating large increases in the heaviest rain rates associated with El Niño. Models with an extreme mode response to global warming do not agree as well with observations of the rainfall response to El Niño.
\end{abstract}

\section{Introduction}

The frequency and intensity of rain are expected to change due to global warming (Trenberth 1999). There are also indications that they change on shorter time scales. What is the present day distribution of rain frequency and intensity, and how do the frequency and intensity of rain change in response to warming?

Rainfall and its changes are often considered from the perspective of the mean or the extremes (e.g., Allen and Ingram 2002). We approach the problem by instead considering the whole distribution and how it changes, which includes the mean and extremes but also their context. In preparation for understanding the distribution of rain, we consider carefully the best way to quantify it.

A variety of approaches to quantifying the distribution of rain can be found in the scientific literature, including different spatial and temporal resolution, bin

\footnotetext{
* Supplemental information related to this paper is available at the Journals Online website: http://dx.doi.org/10.1175/JCLI-D14-00182.s1.

Corresponding author address: Angeline G. Pendergrass, NCAR, P.O. Box 3000, Boulder, CO 80307.

E-mail: apgrass@ucar.edu
}

structure, and wet-day threshold. Some potential temporal resolutions include daily rainfall accumulation and instantaneous, hourly, 6-hourly, 5-day, or monthly data. Stephens et al. (2010) argue that instantaneous rain rate is the best variable to consider, while Trenberth et al. (2003) recommend hourly. Liu and Allan (2012) argue, however, that averaging of observational data is necessary for purposes of intercomparison. They show that the distributions of precipitation in satellite data and gridded analyses agree better when averaged over 5 days than for daily or instantaneous data. Daily satellite observations are the average of only two snapshots, while the daily merged, gridded products have implicit averaging. Other recent studies use monthly-mean data to look at the distribution of rain (Liu et al. 2012; Lau et al. 2013). This removes all variability on less than monthly time scales, which is not desirable if one is interested in possible changes in extremes.

The choice of rain-rate bin structure is fundamental to all rainfall distribution calculations. Rain rate, even accumulated over a day, varies by over orders of magnitude from day to day and from one location to another. A wide variety of possible bin structure choices can be found in the scientific literature. Some studies use linearly distributed rain-rate bins, often with $1 \mathrm{~mm} \mathrm{day}^{-1}$ spacing (e.g., Chou et al. 2012). Linear spacing of bins has the benefit that the bins are related in an obvious 
way, but a substantial drawback is that the bins do not have reasonable sampling at high rain rates. Other studies use irregular bin spacing to improve sampling and capture the entire distribution, but this may make it intractable to work with the distribution mathematically. Watterson and Dix (2003) use logarithmically distributed rain-rate bins. This coordinate makes mathematical operations tractable and captures the entire distribution from light to heavy rain with adequate sampling.

Gridded observations and model data represent a spatial average rather than a single point in space, so that an objective threshold for when it is raining is not obvious. Some studies and guidelines define wet days as having a minimum accumulation of $1 \mathrm{~mm}$ (Sun et al. 2006; Klein Tank et al. 2009). Other studies extend the dry threshold to $0.1 \mathrm{~mm} \mathrm{day}^{-1}$ (e.g., Chou et al. 2012).

The area over which averages are taken also influences the interpretation of rainfall statistics. Some studies (e.g., Pall et al. 2007; O'Gorman and Schneider 2009) take a zonal-mean perspective, in which expected shifts of the ITCZ and storm tracks are prominent. Watterson and Dix (2003) look at the changes in distributions at individual locations. For changes in precipitation at many locations (and thus for impacts of precipitation change), geographical shifts in precipitation systems may dominate over thermodynamic effects.

Spatial resolution of precipitation data has been identified as a contributing factor to disagreements among observational datasets and between models and observations (Chen and Knutson 2008; Kopparla et al. 2013). Both daily gridded data and model data have implicit spatial averaging, so in this sense they are fundamentally different from station data, which measure a particular location.

Extreme precipitation is typically quantified by the rain rate for some cumulative percentile of the rain frequency distribution (e.g., Allen and Ingram 2002; Pall et al. 2007; O'Gorman and Schneider 2009). There are large differences in the extreme precipitation response to interannual variability and longer-time-scale climate changes in models (O'Gorman 2012; Allan et al. 2013).

The goal of this study is to quantify ways the distribution of rain could change over time. To accomplish this, we introduce two modes of coherent change of the rain amount distribution: an increase in rain amount at all rain rates (the increase mode) and a shift of the rain amount distribution to higher rain rates (the shift mode). The increase mode changes the total amount of rain, while the shift mode does not. We apply these two modes to the responses of modeled and observed distributions over phases of El Niño-Southern Oscillation (ENSO). In a companion paper, Pendergrass and Hartmann (2014b), we explore the response to global warming in climate model simulations more extensively and discuss the role that the modes of change play in the energetic and moisture constraints on precipitation.

In the next three sections, we introduce the GCM and observational datasets we will use, present our methodology for calculating the rainfall distribution, and consider the climatological rainfall distributions. In section 5, we discuss the two modes of change. Then, in section 6 , we fit the modes of change to the rain amount response to ENSO phases in observations and models from phase 5 of the Coupled Model Intercomparison Project (CMIP5) and make comparisons with the response to increasing $\mathrm{CO}_{2}$ documented in Pendergrass and Hartmann (2014b).

\section{Daily rainfall data}

In this section, we document the GCM simulations and observational datasets. We analyze daily rainfall accumulation from models and observations. Daily gridded data strike a compromise by providing some temporal averaging but not more than is necessary to make (gridded) observations comparable with models.

For observational distributions of rainfall and its response to ENSO phases, we use two gridded observational datasets that merge data from satellite and rain gauges. Global Precipitation Climatology Project (GPCP) One-Degree Daily (1DD) data (Huffman et al. 2001) have global coverage at $1^{\circ}$ resolution in latitude and longitude. We use data from 1997 to 2012. Tropical Rainfall Measuring Mission (TRMM) 3B42 version 7 (Huffman et al. 2007) covers $50^{\circ} \mathrm{S}-50^{\circ} \mathrm{N}$ at $0.25^{\circ}$ resolution from 1998 to 2012.

To determine ENSO phase, we obtain the monthly time series of SSTs in the Niño-3.4 region $\left(5^{\circ} \mathrm{N}-5^{\circ} \mathrm{S}, 170^{\circ}-\right.$ $120^{\circ} \mathrm{W}$ ) from the National Oceanic and Atmospheric/ Administration Earth System Research Laboratory/ Physical Sciences Division (NOAA/ESRL/PSD; http://www.esrl.noaa.gov/psd/data/climateindices/list) and calculate a Niño-3.4 index following Trenberth (1997). For the warm phase composite, we choose the months with the highest Niño-3.4 index. We use 50 months for observations and 100 months for Atmospheric Model Intercomparison Project (AMIP) simulations (to make use of the longer model simulations). Because we cannot remove the seasonal cycle when calculating the rainfall distribution, it is important to make sure we use the same months of the year in the warm and cold phases. To enforce this requirement, we choose cold months so that the distribution of months is the same as for the warm months. For example, five of the warm months over the GPCP period are January, so 
we choose the five coldest Januaries for the cold phase. We use Hadley Centre/Climatic Research Unit surface temperature anomalies, version 4 (HadCRUT4; Jones et al. 2012) to calculate the observed change in tropical $\left(30^{\circ} \mathrm{S}-30^{\circ} \mathrm{N}\right)$ surface temperature from cold to warm ENSO phase ( $0.35 \mathrm{~K}$ for the GPCP period).

To examine the modeled response to ENSO, we use the AMIP experiments from the CMIP5 archive (Taylor et al. 2012). (The models used and their resolutions are listed in Table S1 of the supplemental material.) In AMIP experiments, sea surface temperature (SST) is prescribed from observations over the historical period, along with prescribed historical forcings. These experiments allow us to examine the modeled response to ENSO SST forcing despite that not all models have good ENSO responses when run in coupled mode. We use one ensemble member from each of the 27 models with archived daily precipitation data from 1979 to 2007. This time period overlaps with but is longer than the observational time period. We normalize by each model's tropical mean surface air temperature change from cold to warm ENSO phase. We choose warm and cold ENSO months based on the same Niño-3.4 dataset index we use for observational data, which is possible because the SSTs are prescribed in the models.

To calculate the model precipitation distributions and their response to $\mathrm{CO}_{2}$ doubling, we use climate model simulations from the CMIP5 archive. We use simulations from two experiments: $1 \% \mathrm{yr}^{-1} \mathrm{CO}_{2}$ increase (1pctCO2) and representative concentration pathway (RCP) with radiative forcing reaching $8.5 \mathrm{~W} \mathrm{~m}^{-2}$ near 2100 (RCP8.5). The fully coupled $1 \mathrm{pctCO} 2$ scenario provides the response to $\mathrm{CO}_{2}$ doubling, initialized from a preindustrial base state. We compare years 1-10 (the start of the simulation) and years 61-70 $\left(\mathrm{CO}_{2}\right.$ doubles at year 70$)$. We use one ensemble member from each of the 22 models with archived daily rainfall accumulation and surface air temperature. From the RCP8.5 simulations, which are initialized from historical forcing in 2005, we compare 2006-15 with 2090-99.

\section{Calculating rain amount and rain frequency}

Next, we discuss the methodology for calculating distributions of rain amount and frequency and their changes. We use logarithmically distributed rain-rate bins following Watterson and Dix (2003). In log coordinates, each rain-rate bin is a fixed percentage wider than the previous one and has a bin center the same percentage larger. We choose bin spacing of $7 \%$ to balance resolution and sampling. For example, one rainrate bin is centered at $10.6 \mathrm{~mm} \mathrm{day}^{-1}$ and has a width of $0.78 \mathrm{~mm} \mathrm{day}^{-1}$, while the next bin is centered at $11.4 \mathrm{~mm} \mathrm{day}^{-1}$ and has a width of $0.84 \mathrm{~mm} \mathrm{day}^{-1}$. The smallest nonzero bin is centered at $0.03 \mathrm{~mm} \mathrm{day}^{-1}$ and has a width of $0.0025 \mathrm{~mm} \mathrm{day}^{-1}$, and the largest bin needed for CMIP5 model data is centered at $663 \mathrm{~mm} \mathrm{day}^{-1}$ and has a width of $49.0 \mathrm{~mm} \mathrm{day}^{-1}$. Bins include all rain rates in the dataset greater than $0.03 \mathrm{~mm} \mathrm{day}^{-1}$. Because of the logarithmic structure, movement along the rain-rate axis is expressed as a percentage change in rain rate. A 7\% increase in rain rate is simply a movement of one rain-rate bin.

Another specification that must be chosen is the threshold used to define dry days. We use a dry threshold of $0.0321 \mathrm{~mm} \mathrm{day}^{-1}$. While most dry days have zero rainfall, in GPCP $3 \%$ of days have rainfall that is nonzero but below the dry threshold. We miss a negligible amount of the total rainfall $(0.014 \%$ in GPCP) by ignoring the rain amount below the dry threshold.

Focusing on the global scale allows us to integrate over spatial shifts in precipitating systems, like the ITCZ and storm tracks, which occur with climate change. To address differing spatial resolution of datasets, when comparing two distributions, we coarsen the higher spatial-resolution precipitation data using an averaging scheme that conserves the total amount of rain (Jones 1999) before calculating the distribution. We coarsen the $0.25^{\circ} \mathrm{TRMM}$ data to the $1^{\circ} \mathrm{GPCP}$ grid. Model resolution ranges from $0.75^{\circ}$ to $2.8^{\circ}$ (for models analyzed from the $\mathrm{CO}_{2}$-increase experiment). We coarsen the GPCP data to model grids when the model resolution is coarser than $1^{\circ}$ and coarsen neither GPCP nor the model for the two models with resolution finer than $1^{\circ}$.

With these decisions about coordinate system, dry threshold, and spatial averaging made, we calculate the distribution of rain frequency and amount. At each grid point, we calculate a rain histogram and normalize by the number of days to form the rain frequency distribution. We also tabulate the total amount of rain that falls in each rain-rate bin to form the rain amount distribution. Then we take the area-weighted average of the distributions over the globe to obtain global-mean distributions. A mathematical description of how we calculate the distributions is presented in the appendix.

We calculate rain amount and rain frequency distributions separately for the first $10 \mathrm{yr}$ of the $\mathrm{CO}_{2}$-doubling model simulations and the $10 \mathrm{yr}$ immediately prior to doubling (years 61-70) as well as for the warm and cold phases of ENSO. We report the absolute changes in rain frequency and rain amount. Some studies report the percentage change of rain frequency and amount distributions (e.g., Sun et al. 2007; Lau et al. 2013), but this has some undesirable properties. The maximum rain rate increases with warming, so for the highest rain rates the percent change in the distribution is not defined. The percentage change will also depend very strongly on the bin structure used. For these reasons, we look at absolute changes in the rain frequency and amount distributions. 
Extreme precipitation is typically quantified by the rain rate for some cumulative percentile of the rain frequency distribution (e.g., Allen and Ingram 2002; Pall et al. 2007; O'Gorman and Schneider 2009). Using our global distribution of rain frequency, we form the cumulative probability distribution of rainfall. We include both wet and dry days, following other studies (e.g., O'Gorman and Schneider 2009). We then interpolate the rain rates from this cumulative distribution onto a logarithmic percentile axis to compare the rate rain as a function of percentile between an initial distribution and a later one. We report the percent change in rain rate at a given percentile of the distribution. The large range of rain rates makes relative change a convenient metric.

Last, we put error bounds on our calculated distributions. To estimate the error in model simulations, we use the spread across models as a measure of variability and determine the $95 \%$ confidence interval using Student's $t$ test assuming each model is independent. This method will underestimate the true uncertainty since climate models are not independent (Masson and Knutti 2011; Pennell and Reichler 2011). To estimate the error of our observed composites, we calculate the distribution for each month of the 50 months of data separately and then determine the $95 \%$ confidence interval using the difference-of-means test.

\section{The rain amount distribution}

In this section, we look at similarities and differences among modeled and observed rain amount and rain frequency distributions. The global-mean distributions of rain amount and rain frequency for both GPCP and the CMIP5 multimodel mean are shown in Fig. 1. The multimodel mean is taken from the first $10 \mathrm{yr}$ of the RCP8.5 simulation so that the time period is similar to (though not exactly the same as) the GPCP time period. To address potential inconsistency between models and observations due to their differing resolution, the GPCP distribution is calculated as follows: The GPCP data are coarsened to each model's grid, the distribution of the coarsened GPCP data at each grid point is calculated, each distribution of coarsened data is averaged globally, and then the global distributions are averaged together to obtain the distributions shown in Fig. 1. The GPCP and model rain amount distributions agree broadly. They both peak around $10 \mathrm{~mm} \mathrm{day}^{-1}$ and are in agreement for moderate rain rates. However, the model rain amount is slightly higher at the highest and lowest rain rates. The GPCP rain amount distribution is narrower than the multimodel mean. The area under the rain amount curve is the global-mean rainfall, which is lower in GPCP, at $2.7 \mathrm{~mm} \mathrm{day}^{-1}$, than in the models, at $2.9 \mathrm{~mm}$ day $^{-1}$. Stephens et al. (2012) argued that GPCP (a)

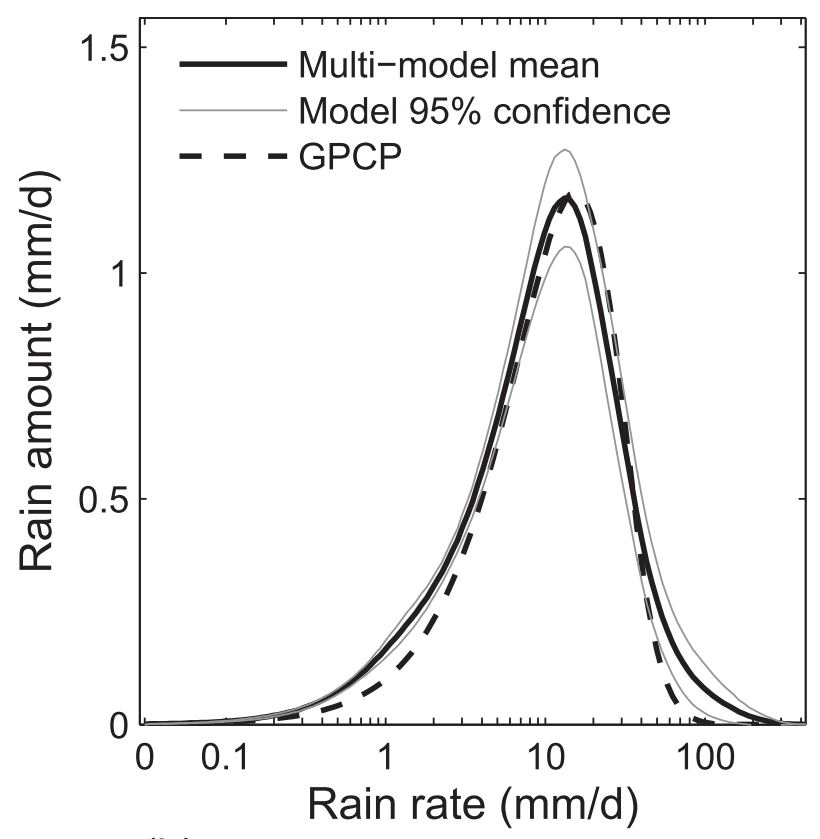

(b)

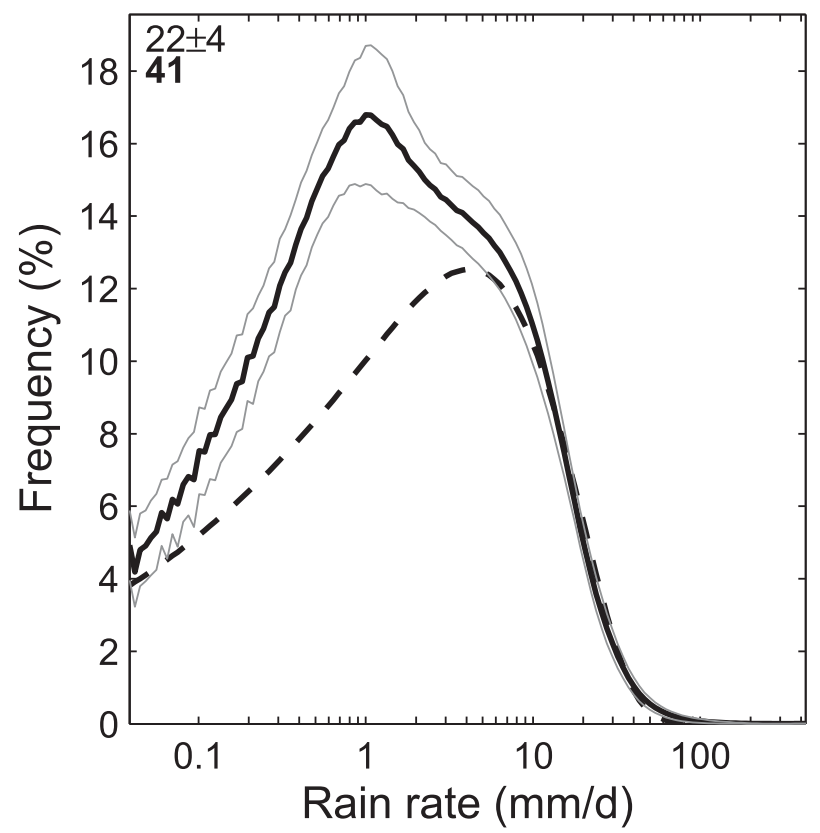

FIG. 1. Global (a) rain amount $\left(\mathrm{mm} \mathrm{day}^{-1}\right)$ and (b) rain frequency distribution (\%) climatologies in CMIP5 models and GPCP observations of daily rainfall. Dry-day frequency is noted at the top left of (b), with models (normal) and GPCP (thick). GPCP gridded observations are coarsened before distributions are calculated. Gray lines show the $95 \%$ confidence interval on the multimodel mean according to Student's $t$ test across the model distributions. 
underestimates the total rainfall compared to what is needed to balance observed atmospheric radiative cooling.

The multimodel-mean rain frequency distribution agrees relatively well with GPCP above about $10 \mathrm{~mm} \mathrm{day}^{-1}$ (Fig. 1b). At lighter rain rates, between about 0.1 and $5 \mathrm{~mm}$ day $^{-1}$, models have a much higher frequency of rain than GPCP. Modeled rain frequency peaks at $1.1 \mathrm{~mm}$ day $^{-1}$, where it is nearly twice as frequent as GPCP, while the GPCP rain frequency peaks at $10.6 \mathrm{~mm}$ day $^{-1}$. Models and GPCP disagree drastically on the dry-day frequency. The dry-day frequency is $22 \%$ in the multimodel mean but $41 \%$ in GPCP. Extending the precipitation bins below $1 \mathrm{~mm}$ day $^{-1}$ heightens the discrepancy compared to studies that include this light rain in the dry-day count.

Most models have a shape similar to GPCP (see Fig. S1 in the supplemental material; see also Pendergrass 2013), with a peak somewhere slightly above $10 \mathrm{~mm}^{\mathrm{day}}{ }^{-1}$. Some models have an extra feature on the high end of the distribution, while others have an extra bump at light rain rates. Many models have distributions that closely resemble GPCP, including the MPI-ESM models (Mauritsen et al. 2012).

TRMM and GPCP datasets agree on the general shape of the distribution but disagree on many details (Fig. S2 in the supplemental material). TRMM has a broader distribution of rainfall than GPCP, with more rain at low and high rain rates, particularly over ocean. The datasets agree closely on the total amount of precipitation. Overall, GPCP and TRMM show better agreement on rain amount than rain frequency, just as GPCP and models agree better on total amount than frequency.

The rain amount distribution emphasizes higher rain rates more than the rain frequency distribution does. Models and observations agree better at higher rain rates than lower ones, so the modeled rain amount distribution is more similar to GPCP than the frequency distribution. The similarity in rain amount despite differences in rain frequency could be anticipated because rain amount is an important factor in the energy budget, and models are roughly in energetic balance. On other side of this coin, having many or few light rain events makes only a small difference in terms of latent heating and so are not strongly constrained by the energy balance.

\section{The shift and increase modes of change}

We focus our analysis on the change in each distribution relative to its own base state to account for the differences in climatological distributions among models and observations. There is no need to assume an underlying functional form (e.g., gamma or lognormal) of the distribution for our analysis.

\section{Two modes of change: Shift and increase of rain amount}

In this section, we will formulate some simple modes of change of the rain amount distribution. Before considering changes in rain, we must define some terms. The rain rate $r$ is in millimeters per day, though we will work in coordinates of $\ln r$. The cumulative rain amount $P(r)$ is

$$
P(r)=\int_{\ln r_{\min }}^{\ln r} p(\ln \dot{r}) d \ln \dot{r},
$$

where $p(\ln r)$ is the rain amount distribution. Dots indicate placeholder variables over which the integral is taken. The units of $P$ are millimeters per day, and $p=d P / d \ln r$. Then the total rainfall (the global-mean precipitation) is $\bar{P}=P(\infty)=P\left(r_{\max }\right)$. The dry-day threshold is $r_{\min }$, and the maximum daily rainfall in our dataset is $r_{\max }$. We assume $P\left(r_{\min }\right)=0$. The cumulative frequency distribution of rain $F(r)$ is

$F(r)=\int_{-\infty}^{\ln r} f(\ln \dot{r}) d \ln \dot{r}=F_{d}+\int_{\ln r_{\min }}^{\ln r} f(\ln \dot{r}) d \ln \dot{r}$,

where $f(\ln r)$ is the rain frequency distribution, $F(\infty)=$ $F\left(r_{\max }\right)=1$, and $F_{d}=F\left(r_{\min }\right)$ is the dry-day frequency. The rain amount $p$ and rain frequency $f$ distributions are related by

$$
p(\ln r)=r f(\ln r) .
$$

We have $d \ln r=d r / r$, and as long as changes are small, we can approximate the infinitesimal changes with finite ones $(\Delta \ln r=\Delta r / r)$, expressed as a percentage. Changed distributions will be indicated by primes $\left(f^{\prime}\right.$, $p^{\prime}$, and $F_{d}^{\prime}$ ).

How might the distribution of rain amount and rain frequency respond to changes in climate? One way rain could change is that it could become more frequent. The shape of the distribution of rain when it is raining would stay the same, but it would rain more often, with more rain falling at each rain rate. We will call this mode the increase mode. If the rain increases by a fraction $a$ at each rain rate,

$$
\begin{aligned}
& p^{\prime}(\ln r)=(1+a) p(\ln r), \text { which also requires } \\
& f^{\prime}(\ln r)=(1+a) f(\ln r)
\end{aligned}
$$

The increase mode results in a decreased dry-day frequency, $F_{d}^{\prime}=1-(1+a)\left(1-F_{d}\right)$, and an increase in total rainfall $\overline{P^{\prime}}=(1+a) \bar{P}$. The increase or decrease in rain must be balanced by a corresponding increase or decrease in total atmospheric cooling. We can also have negative $a$, where the total precipitation and frequency of rainfall decrease. 
(a)
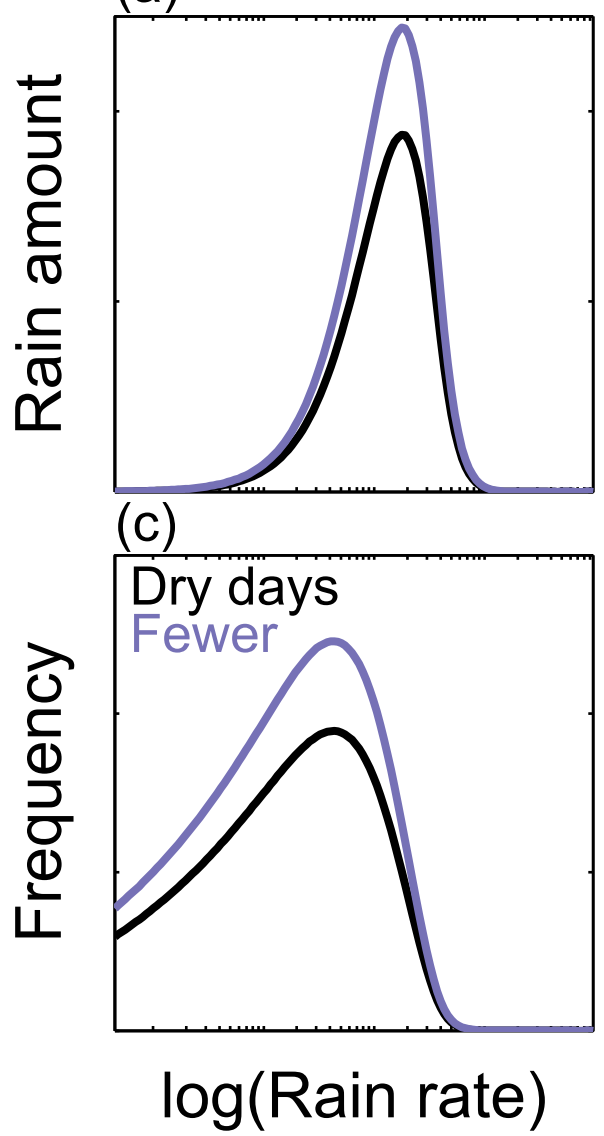

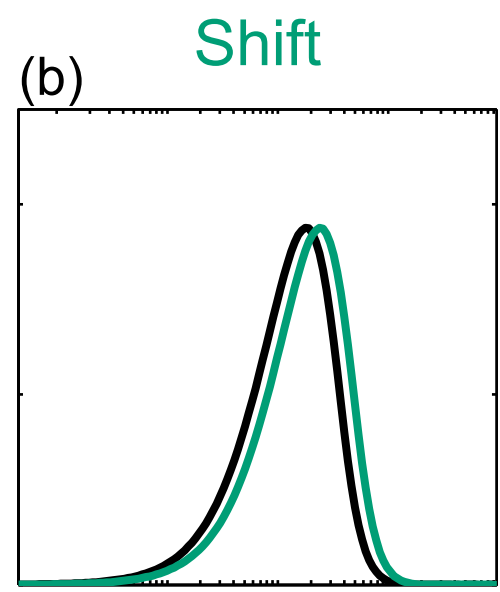

(d)

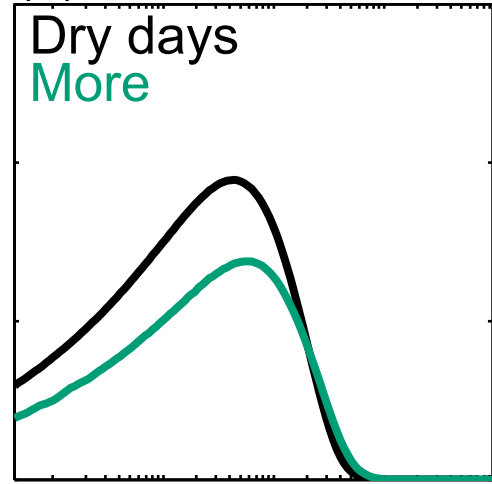

$\log$ (Rain rate)

FIG. 2. Schematic of the modes of change of the rain distribution introduced here: (a),(c) the increase (purple) and (b),(d) the shift (green) in (a),(b) the rain amount distributions and (c),(d) the accompanying rain frequency distributions. Initial distributions from GPCP are shown in black, and the new distributions resulting from a large (30\%) shift or increase are shown in color.

A response consisting of the increase mode alone is unlikely for several reasons. For example, it does not allow for an increase in the maximum rain rate. We expect that the rainfall intensity will increase where convergence occurs or where air flows over topography by at least $7 \% \mathrm{~K}^{-1}$ because the specific humidity will increase with temperature. However, the magnitude of global-mean precipitation increase is limited by energetic constraints to be $1 \%-2 \% \mathrm{~K}^{-1}$ (e.g., Pendergrass and Hartmann 2014a). For the increase in global-mean precipitation to occur at a different rate than events driven by convergence and upward motion, which are generally the events with the highest rain rates, the shape of the precipitation distribution must change.

Another possible response is that the rain amount distribution could shift to higher rain rates. Then, the same amount of rain would fall, but at higher rain rates. If the distribution stays the same shape, enclosing the same total area, then this change will be energetically neutral, not requiring a change in atmospheric radiative cooling. If the distribution shifts to the right by $b=\Delta r / r$, then this shift mode is

$$
p^{\prime}(\ln r)=p(\ln r-b) .
$$

If the same amount of rain falls at higher rain rates, then less time is spent raining. So, we should expect the rain frequency to decrease and dry-day frequency to increase with the shift mode. With some algebra, we obtain the new frequency distribution,

$$
\begin{aligned}
f^{\prime}(\ln r) & =e^{-b} f(\ln r-b) \quad \text { and } \\
F_{d}^{\prime} & =1-\frac{1-F_{d}}{e^{b}} .
\end{aligned}
$$

The total rainfall does not change, so $\overline{P^{\prime}}=\bar{P}$. A schematic of the increase and shift modes is shown in Fig. 2. 
The modes we have chosen have convenient mathematical forms and focus on key energetic concepts, but others are possible. For example, one can imagine a mode where the shape of the rain frequency distribution and the total frequency of rain do not change, but rain amount increases when it is raining. This would be a shift of the rain frequency distribution to higher rain rates, $f^{\prime}(\ln r)=f(\ln r-\Delta \ln r)$, analogous to the shift of the rain amount distribution in the shift mode. In fact, this movement of the rain frequency distribution with no change in shape is equivalent to the shift and increase modes simultaneously changing by the same amount, $a=b$ (for small changes $a, b \ll 1$ when $f$ and $p$ can be linearized). Because this mode is degenerate with the sum of the shift mode and the increase mode, we will not calculate it independently.

We can calculate the magnitudes of the shift and increase modes that produce the closest possible fit to the modeled or observed response to warming. We will call their superposition the "shift plus increase." To optimize the shift plus increase, we make some assumptions. First, we assume that all changes are small, so changes in $p$ can be linearized,

$$
p(\ln r-b) \approx p(\ln r)-b \frac{d p}{d \ln r} .
$$

The model distribution and its response are discrete distributions, so we use a discrete approximation. Next, we must choose an error metric. We choose the sum of the square of the difference between the shift plus increase and the observed or model response, $E=$ $\Sigma\left(\Delta p-\Delta p^{m}\right)^{2}$, where $\Delta p^{m}$ is the model response, $\Delta p=$ $p^{\prime}-p$, and the sum is taken over all $r$ bins.

To fit the magnitude of the increase and shift, $a$ and $b$, we find where $E$ has a local minimum with respect to each of $a$ and $b$. This produces the following twovariable linear set of equations,

$$
\left[\begin{array}{cc}
\Sigma p^{2} & -\Sigma p \frac{d p}{d \ln r} \\
-\Sigma p \frac{d p}{d \ln r} & \Sigma\left(\frac{d p}{d \ln r}\right)^{2}
\end{array}\right]\left[\begin{array}{l}
a \\
b
\end{array}\right]=\left[\begin{array}{c}
\sum p \Delta p^{m} \\
-\sum \frac{d p}{d \ln r} \Delta p^{m}
\end{array}\right]
$$

The optimal shift plus increase for the multimodelmean response to $\mathrm{CO}_{2}$ increase is shown in Fig. 3. The magnitude of the shift mode is $3.3 \% \mathrm{~K}^{-1}$ and the increase mode is $0.9 \% \mathrm{~K}^{-1}$. Between about 1 and $50 \mathrm{~mm} \mathrm{day}^{-1}$, the shift plus increase falls within the range of uncertainty in the model response. At the highest rain rates and at light rain rates, the shift plus increase underestimates the rain amount response, which we discuss

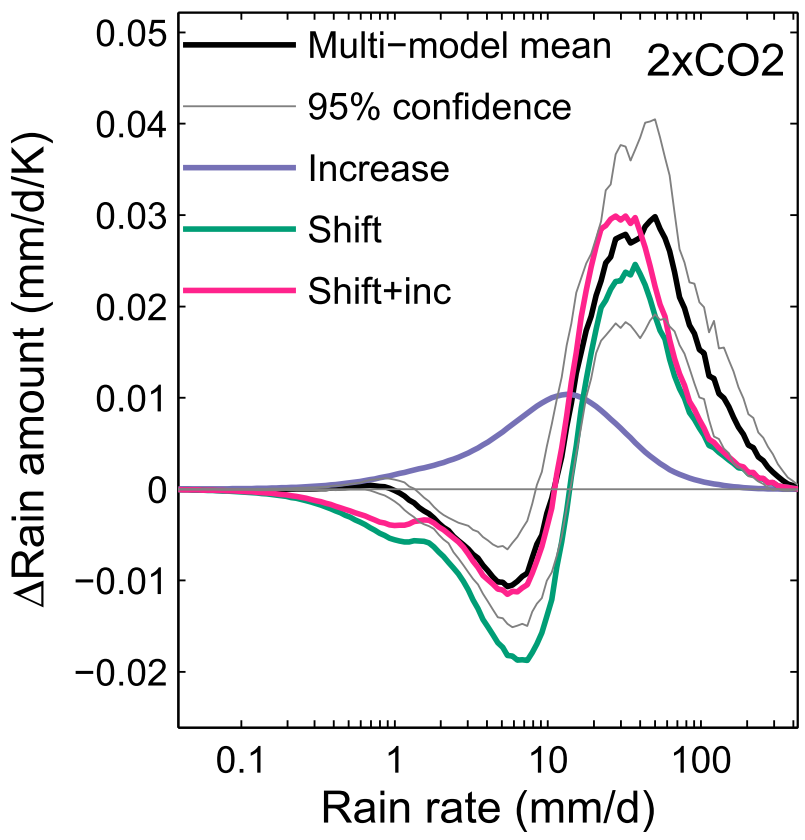

FIG. 3. CMIP5 multimodel-mean rain amount response to $\mathrm{CO}_{2}$ doubling normalized by the increase in global-mean surface air temperature $\left(\mathrm{mm} \mathrm{day}^{-1} \mathrm{~K}^{-1}\right)$. The model response (black), increase (purple), shift (green), and shift plus increase (pink) are shown. Gray lines show $95 \%$ confidence interval of the multimodelmean response.

extensively in Pendergrass and Hartmann (2014b). The sum of squared differences will emphasize the largest differences, but we are more interested in how much of the change in rainfall is captured by the response. We report the error in terms of how much of the precipitation response it fails to capture,

$$
\text { Error }=\frac{\Sigma\left|\Delta p-\Delta p^{m}\right|}{\Sigma\left|\Delta p^{m}\right|} .
$$

\section{Response to ENSO phases in models and observations}

In this section, we ask the following: Do the shift and increase in the rain amount distribution provide a good description of observed rainfall change? Gridded daily observational precipitation datasets only go back to 1997, so at present we would not expect to see statistically significant global trends in rain frequency or rain amount in observations. Instead of looking at trends, we explore the response of tropical rain to ENSO. We look at changes in tropical $\left(30^{\circ} \mathrm{S}-30^{\circ} \mathrm{N}\right)$ precipitation in the GPCP 1DD and TRMM 3B42v7 datasets (described in section 2) composited over warm and cold phases of 
(a)

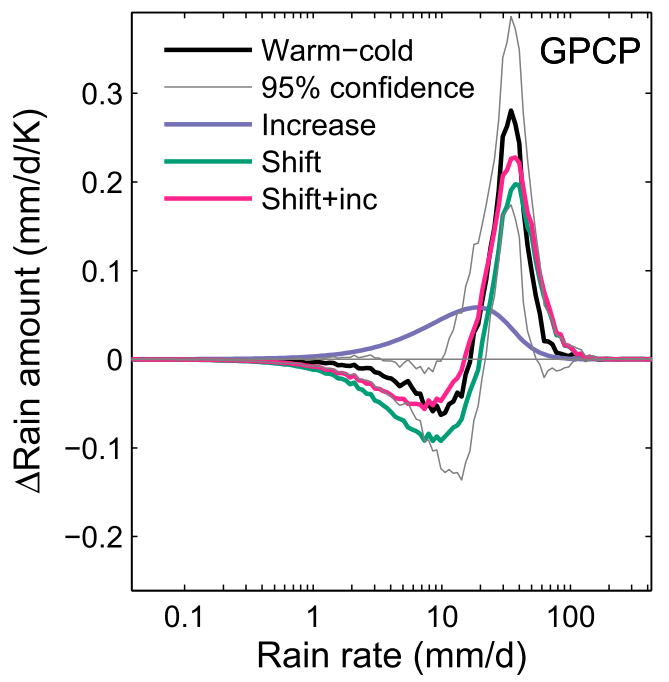

(b)

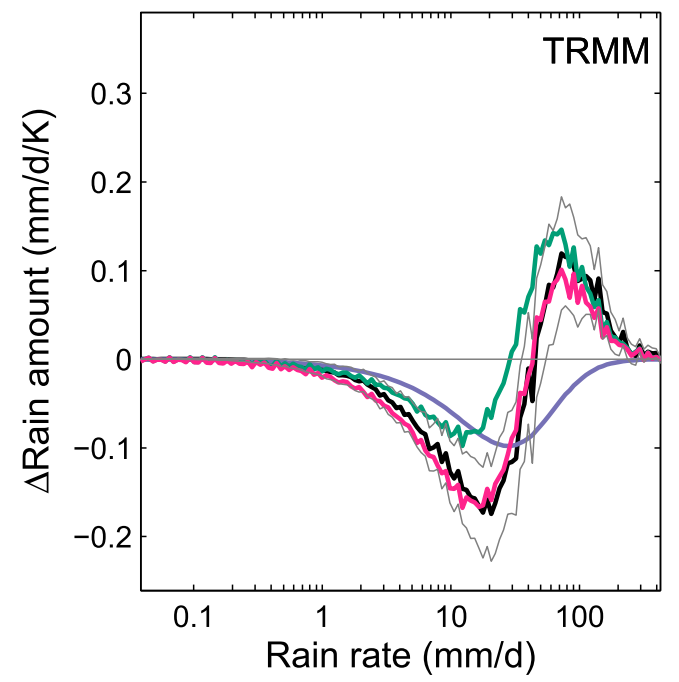

(c)

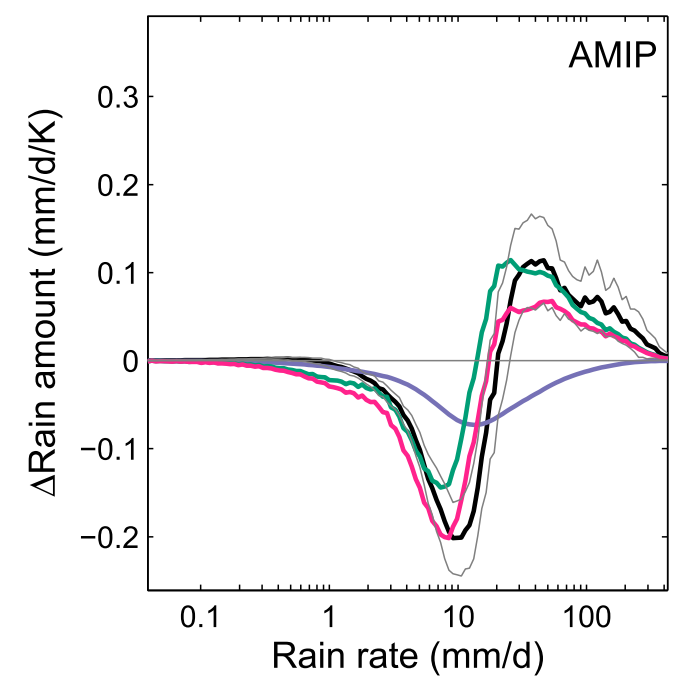

FIG. 4. Rain amount response in the tropics to ENSO phases in (a) GPCP, (b) TRMM, and (c) AMIP models. Warm minus cold ENSO precipitation from GPCP 1 DD over the tropics $\left(30^{\circ} \mathrm{N}-30^{\circ} \mathrm{S}\right)$ is shown. Gray lines show $95 \%$ confidence interval of the change according to the difference-of-means test on the observations.

ENSO. The response to ENSO can be studied in both observations and models. So we can also ask whether model changes are similar to the observed changes.

Figure 4 shows the difference between warm and cold ENSO rain amount distributions (along with the fitted shift and increase modes) for the two sets of observations as well as the multimodel mean. The difference in rain amount distribution crosses zero near the peak of the climatological rain amount distribution, with a local maximum at high rain rates and minimum at lower rain rates. This is consistent with Allan and Soden (2008), though they looked at changes as a function of percentile of the cumulative frequency distribution. GPCP and TRMM observational datasets have qualitatively somewhat different responses. The sharper response seen in GPCP compared to TRMM is consistent with its steeper climatological distribution (Fig. S2).

Table 1 lists the shift, increase, error, and total rainfall response for dataset and region. In all cases, the shiftplus-increase fit the response to ENSO phase within the uncertainty at most rain rates (Fig. 4 and Figs. S3 and S4 in the supplemental material). Figures 5a,c show the magnitude of the shift and increase modes over the whole tropics, sea, and land. Over land, the shift and increase closely fit the rain amount response in all cases (Fig. S3). Both observational datasets and the AMIP models show a large negative increase mode of $25 \%-$ $26 \% \mathrm{~K}^{-1}$ over land, which is slightly larger than the 
TABLE 1. The shift and increase in response to ENSO phases for GPCP and TRMM observations and AMIP model simulations, along with the error of the fit and the change in mean precipitation. For the AMIP simulations, both the fit to the multimodel mean (MMM) and the average of the fit to each model are shown. Temperature changes are taken from tropical average HadCRUT4 for observational datasets and surface air temperature for models.

\begin{tabular}{|c|c|c|c|c|}
\hline Dataset & Shift $\left(\% \mathrm{~K}^{-1}\right)$ & Increase $\left(\% \mathrm{~K}^{-1}\right)$ & Error & $\Delta P\left(\% \mathrm{~K}^{-1}\right)$ \\
\hline \multicolumn{5}{|l|}{ Whole tropics } \\
\hline GPCP & 14 & 6.8 & 0.31 & 6.1 \\
\hline TRMM & 14 & -7.8 & 0.21 & -6.1 \\
\hline AMIP mean of models & 15 & -4.7 & 0.51 & -1.8 \\
\hline AMIP MMM & 15 & -5.2 & 0.49 & -1.8 \\
\hline \multicolumn{5}{|l|}{ Sea } \\
\hline GPCP & 20 & 19 & 0.21 & 17 \\
\hline TRMM & 18 & -0.85 & 0.17 & -0.92 \\
\hline AMIP mean of models & 20 & 2.0 & 0.48 & 3.9 \\
\hline AMIP MMM & 22 & 1.2 & 0.31 & 3.8 \\
\hline \multicolumn{5}{|l|}{ Land } \\
\hline GPCP & -3.6 & -26 & 0.30 & -22 \\
\hline TRMM & -5.7 & -25 & 0.24 & -22 \\
\hline AMIP mean of models & -3.3 & -25 & 0.42 & -21 \\
\hline AMIP MMM & -4.5 & -24 & 0.32 & -21 \\
\hline
\end{tabular}

decrease in total rainfall. The datasets also agree on a shift of rain amount to lighter rain rates, ranging from $-3.3 \%$ to $-5.7 \% \mathrm{~K}^{-1}$. Most of the response to ENSO phase over land is a decrease in rain amount.

Over the ocean, the observational datasets disagree on the response in total rainfall (Fig. 5c). Interannual variability over the ocean in the previous version of TRMM, version 6 , was different from other observational datasets (both GPCP and satellite; Liu and Allan 2012). As a result of the difference in the total rainfall response, the observational datasets disagree on the sign of the increase mode over ocean. TRMM has a decrease of $6.1 \% \mathrm{~K}^{-1}$, while
GPCP has an increase of $6.1 \% \mathrm{~K}^{-1}$. AMIP models fall in between the two, with $1.8 \% \mathrm{~K}^{-1}$ of decrease. The changes in atmospheric energy balance over ENSO are unlikely to be the same as in response to $\mathrm{CO}_{2}$ increase because both the nature of the forcing and the spatial structures of the changes are different. Energy transport into and out of the tropics plays an important role in the relationship between tropical surface temperature and precipitation ( $\mathrm{Su}$ and Neelin 2003), unlike in the global average case.

The observational datasets and AMIP models agree on a shift between $18 \%$ and $22 \% \mathrm{~K}^{-1}$ over ocean (Fig. 5a), despite the disagreement in total rainfall response. The rain (a) Response to ENSO phases

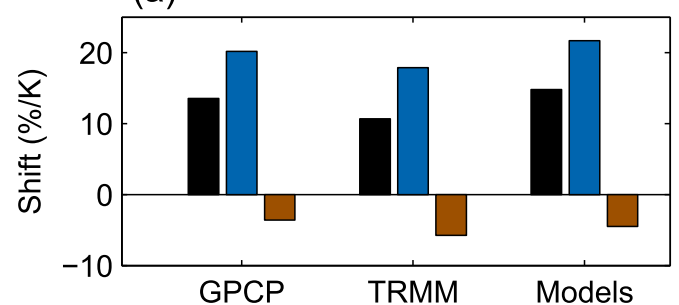

(c)

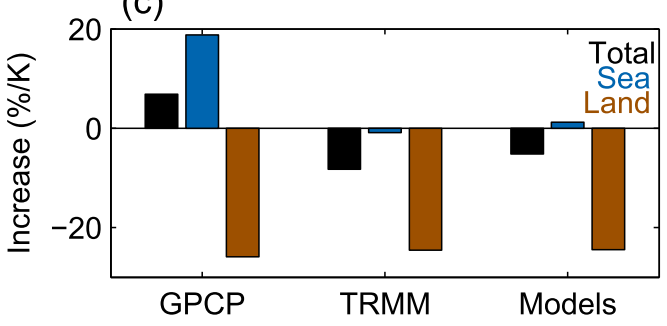

(b)

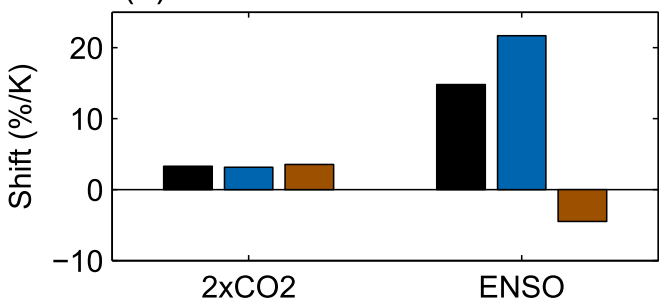

(d)

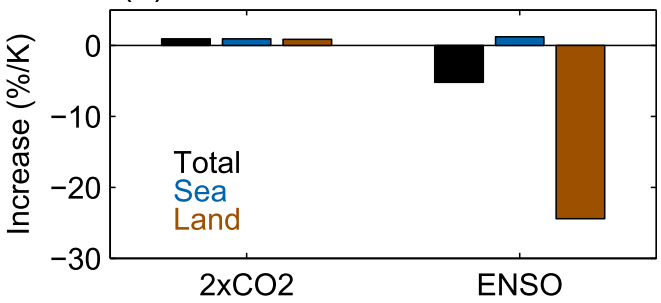

FIG. 5. (a),(b) The shift and (c),(d) the increase modes fit to (a),(c) the tropical response to ENSO phases in the CMIP5 multimodel mean and (b),(d) the global response to $\mathrm{CO}_{2}$ increase. Units are percent per kelvin. The total (black), ocean (blue), and land (brown) are included. 
(a)

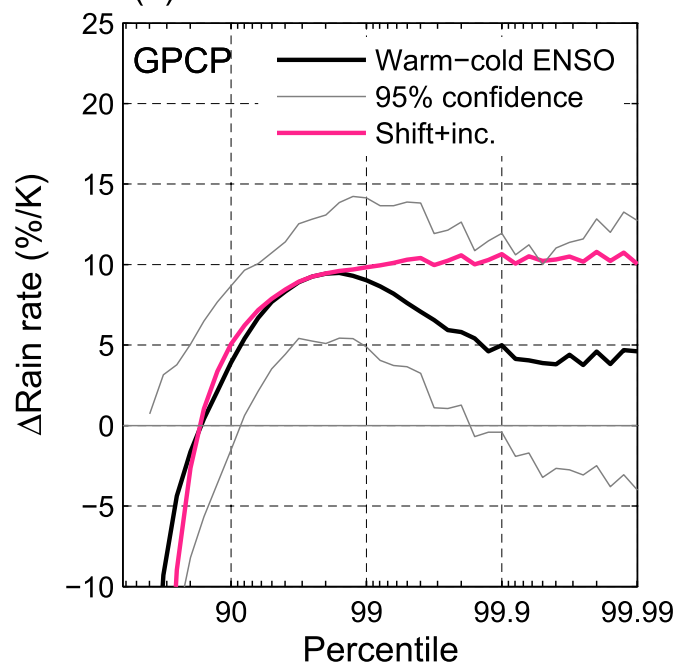

(b)

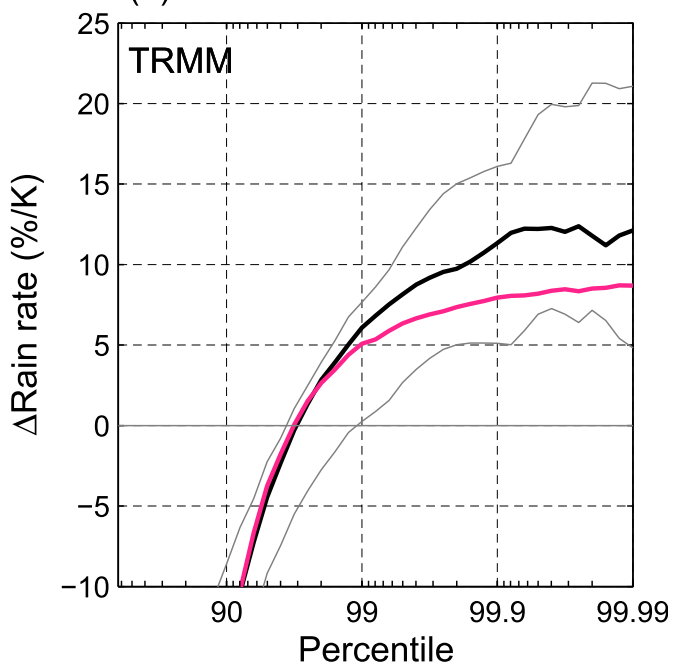

(c)

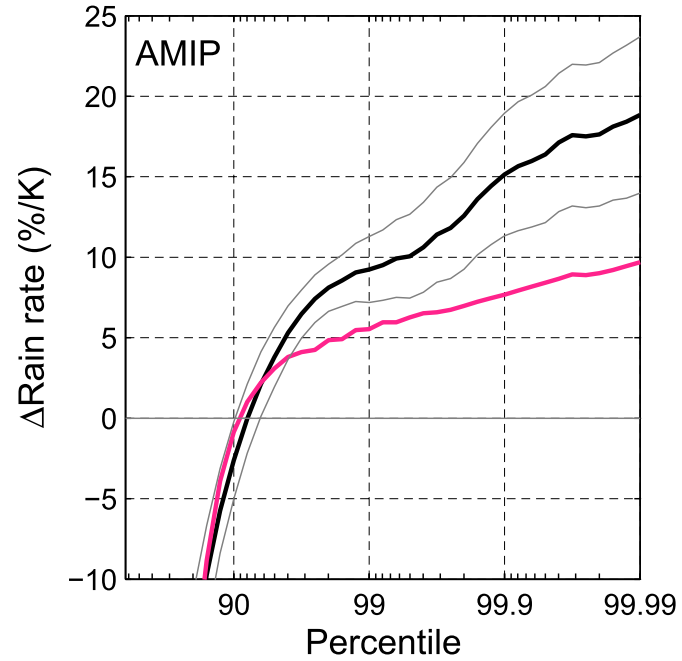

FIG. 6. Extreme precipitation response $\left(\% \mathrm{~K}^{-1}\right)$ to ENSO phases in (a) GPCP and (b) TRMM observations and (c) AMIP models.

amount response to ENSO is dominated by a shift to higher rain rates in both observational datasets and models.

The response to ENSO phases differs from the response to increasing $\mathrm{CO}_{2}$ [the response to $\mathrm{CO}_{2}$ increase is explored in Pendergrass and Hartmann (2014b)]. Figures 5b,d compare the magnitude of the shift-plus-increase fit to the modeled responses to $\mathrm{CO}_{2}$ increase and ENSO phases. The differences between land and ocean in response to $\mathrm{CO}_{2}$ increase are much smaller than the differences in response to ENSO phases. The magnitude of the shift is much bigger in response to ENSO $\left(15 \% \mathrm{~K}^{-1}\right)$ than in response to $\mathrm{CO}_{2}$ increase $\left(3.3 \% \mathrm{~K}^{-1}\right)$ for the total area and over the ocean. Finally, the increase mode has a larger magnitude in the model response to ENSO phases than in response to $\mathrm{CO}_{2}$ increase.

It is remarkable that the shift and increase fit the rain amount response to ENSO phases in both observations and models. Next we consider the implications of the shift and increase on the extreme events.

\section{a. Extreme events}

Now we turn to the response of the extreme end of the frequency distribution: How does observed tropical extreme precipitation respond to ENSO, and do models capture the observed changes? The response of extreme precipitation to ENSO phases in both observational datasets is shown in Fig. 6. All datasets and the fitted shift plus increases show increases in extreme events beyond the 99th percentile in the tropical mean. At the 99.99th percentile, the increases are highest in AMIP models $\left(19 \% \mathrm{~K}^{-1}\right)$, followed by TRMM $\left(12 \% \mathrm{~K}^{-1}\right)$ and then $\operatorname{GPCP}\left(5 \% \mathrm{~K}^{-1}\right)$. At the 99 th percentile, GPCP (at $\left.10 \% \mathrm{~K}^{-1}\right)$ has more increase than TRMM $\left(5 \% \mathrm{~K}^{-1}\right)$, 
(a)

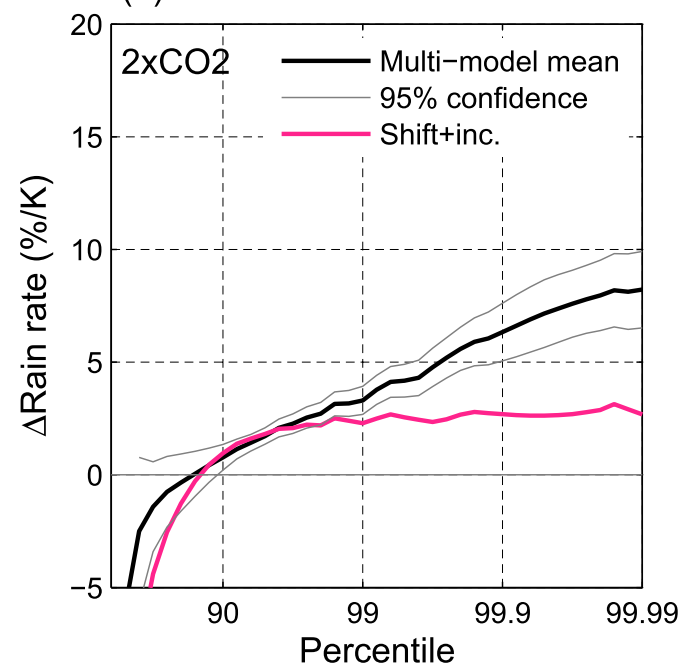

(b)

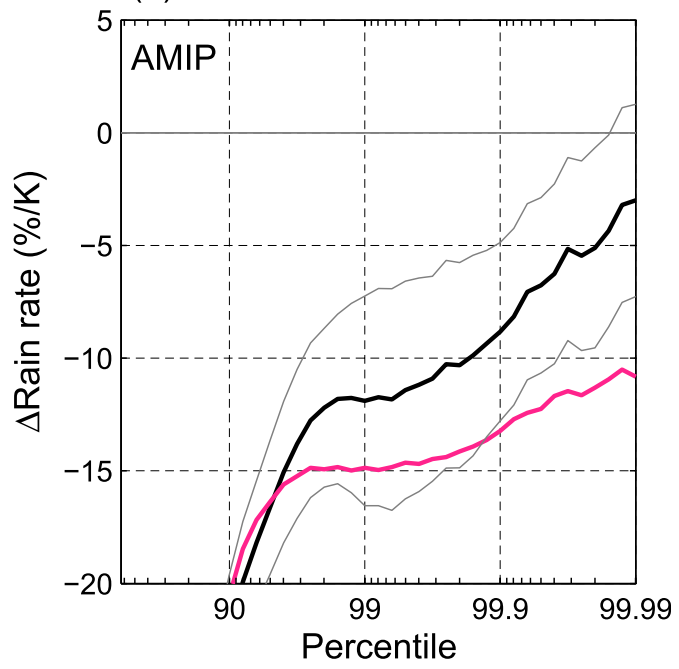

FIG. 7. Change in extremes over land in models in response to (a) $\mathrm{CO}_{2}$ doubling and (b) ENSO phases in AMIP experiments.

while AMIP is similar to GPCP $\left(10 \% \mathrm{~K}^{-1}\right)$. Up to the 99th percentile, the shift plus increase is within the uncertainty in each observational dataset. At the 99.9th and 99.99th percentiles, the shift plus increase underestimates the increase for AMIP models.

The change in extreme precipitation over ocean (Fig. S5 in the supplemental material) follows the same pattern as the whole tropics. GPCP and TRMM responses over land (Fig. S6) are similar to the AMIP response (Fig. 7b). Unlike for $\mathrm{CO}_{2}$ doubling, the response of extreme rain rate over land is very different from the total response (consistent with Allan et al. 2013). The "shift plus decrease" predicts a decrease in rain rate at nearly all percentiles in both observational datasets and AMIP experiment. The only exception is that in GPCP, the most extreme percentiles do not show significant change. The shift plus increase predicts a larger decrease in rain rate at all percentiles beyond the 99th in all datasets over land. The models agree less over land than over ocean, unlike in response to $\mathrm{CO}_{2}$ doubling. The standard deviation of the 99.99th-percentile rain-rate response is $16 \% \mathrm{~K}^{-1}$ over land and $10.8 \% \mathrm{~K}^{-1}$ over ocean. For the entire tropics, the standard deviation among models is lower than for either land or ocean, at just $9.0 \% \mathrm{~K}^{-1}$. This is consistent with shifting of rain (spatially) from land to ocean resulting in some compensation across models.

The increase in extreme precipitation implied by the shift plus increase is tightly tied to the magnitude of the shift mode. The finding that the shift is much greater for changes during ENSO events than for the response to $\mathrm{CO}_{2}$ doubling (by a factor of at least 4 ) is consistent with the finding that the sensitivity of 99.9th-percentile precipitation is 2.5 times greater for interannual variability than for increases expected over the next century in models (O'Gorman 2012). Allan et al. (2013) also found muted increase of extreme precipitation for climate change relative to interannual variability.

Land and ocean could be expected to have different responses to $\mathrm{ENSO}$ or $\mathrm{CO}_{2}$ increase for physical reasons (Trenberth 2011). Figure 7a shows the multimodelmean response to $\mathrm{CO}_{2}$ doubling over land (at all latitudes). It is very similar to the total response, except for somewhat better agreement among models than for the global response. The intermodel standard deviation of 99.99th-percentile increase is $7.2 \% \mathrm{~K}^{-1}$ over ocean and $3.9 \% \mathrm{~K}^{-1}$ over land.

\section{b. Sorting models by comparing their response to ENSO phases with observations}

Can we discern whether some models are more consistent with observations than others by comparing AMIP experiments with observations? O'Gorman (2012) showed that the responses of interannual variability and long-term change in each model's 99.9th-percentile precipitation response are related and used the modeled relationship between interannual variability and long-term change to predict the long-term change based on observed variability. For the 14 models analyzed here with simulations for both RCP8.5 and AMIP experiments, the 99.99th-percentile response due to twenty-first-century climate forcing and ENSO phase are positively correlated, significant at the $90 \%$ (but not $95 \%$ ) confidence level. In these models, the shift mode in response to ENSO phase and RCP8.5 experiments is also correlated (significant at $95 \%$ confidence). If the observed response to ENSO phase clearly favored some models over others, 
TABLE 2. CMIP5 models sorted by whether or not their tropical response to ENSO phases in AMIP simulations are consistent with GPCP and TRMM observed responses. To be considered consistent, a model's shift must be within one standard deviation $\left(6.5 \% \mathrm{~K}^{-1}\right)$ of the observed shift, $14 \% \mathrm{~K}^{-1}$, and its 99.99 th-percentile rain-rate response $\left(\Delta R_{99.99}\right)$ must also fall with the uncertainty range which spans from $-2 \%$ to $21 \% \mathrm{~K}^{-1}$. Only models participating in AMIP as well as either $\mathrm{CO}_{2}$-doubling or RCP8.5 experiments are included. Global responses are shown for $\mathrm{CO}_{2}$-doubling and $\mathrm{RCP} 8.5$ experiments.

\begin{tabular}{|c|c|c|c|c|c|c|c|}
\hline \multirow[b]{2}{*}{ Model } & \multirow[b]{2}{*}{ Expanded model name } & \multicolumn{2}{|c|}{ AMIP } & \multicolumn{2}{|c|}{$2 \times \mathrm{CO}_{2}$} & \multicolumn{2}{|c|}{ RCP8.5 } \\
\hline & & $\begin{array}{l}\text { Shift } \\
\left(\% \mathrm{~K}^{-1}\right)\end{array}$ & $\begin{array}{c}\Delta R_{99.99} \\
\left(\% \mathrm{~K}^{-1}\right)\end{array}$ & $\begin{array}{l}\text { Shift } \\
\left(\% \mathrm{~K}^{-1}\right)\end{array}$ & $\begin{array}{c}\Delta R_{99.99} \\
\left(\% \mathrm{~K}^{-1}\right)\end{array}$ & $\begin{array}{l}\text { Shift } \\
\left(\% \mathrm{~K}^{-1}\right)\end{array}$ & $\begin{array}{c}\Delta R_{99.99} \\
\left(\% \mathrm{~K}^{-1}\right)\end{array}$ \\
\hline \multicolumn{8}{|l|}{ Consistent } \\
\hline BNU-ESM & $\begin{array}{l}\text { Beijing Normal University-Earth } \\
\text { System Model }\end{array}$ & 12 & 3.4 & & & 2.3 & $9.0 \pm 4.7$ \\
\hline CMCC-CM & $\begin{array}{l}\text { Centro Euro-Mediterraneo per I } \\
\text { Cambiamenti Climatici Climate } \\
\text { Model }\end{array}$ & 19 & 2.6 & 1.8 & $8.2 \pm 3.2$ & & \\
\hline CSIRO Mk3.6.0* & $\begin{array}{l}\text { Commonwealth Scientific and } \\
\text { Industrial Research Organisation } \\
\text { Mark 3.6.0 }\end{array}$ & 9.9 & 8.5 & & & 3.6 & $5.0 \pm 2.4$ \\
\hline CanAM4 & $\begin{array}{l}\text { Fourth Generation Canadian Coupled } \\
\text { Atmospheric Global Climate Model }\end{array}$ & 15 & 14 & 2.6 & $8.9 \pm 2.3$ & 1.9 & $7.5 \pm 3.6$ \\
\hline FGOALS-g2 & $\begin{array}{l}\text { Flexible Global Ocean-Atmosphere- } \\
\text { Land System Model, gridpoint } \\
\text { version } 2\end{array}$ & 14 & 8.3 & & & 0.41 & $1.1 \pm 1.9$ \\
\hline INM-CM4.0 & $\begin{array}{l}\text { Institute of Numerical Mathematics } \\
\text { Coupled Model, version } 4.0\end{array}$ & 13 & 9.8 & & & 2.8 & $2.3 \pm 1.4$ \\
\hline IPSL-CM5B-LR* & $\begin{array}{l}\text { L'Institut Pierre-Simon Laplace Coupled } \\
\text { Model, version 5B, low resolution }\end{array}$ & 18 & 20 & 3.7 & $3.4 \pm 2.2$ & 4.0 & $3.2 \pm 3.5$ \\
\hline MPI-ESM-LR & $\begin{array}{l}\text { Max Planck Institute Earth System } \\
\text { Model, low resolution }\end{array}$ & 19 & 17 & 5.7 & $6.3 \pm 2.5$ & 4.7 & $6.8 \pm 2.9$ \\
\hline MPI-ESM-MR & $\begin{array}{l}\text { Max Planck Institute Earth System } \\
\text { Model, medium resolution }\end{array}$ & 17 & 9.8 & 5.6 & $6.9 \pm 2.5$ & & \\
\hline \multicolumn{8}{|l|}{ Not Consistent } \\
\hline ACCESS1.3 & $\begin{array}{l}\text { Australian Community Climate and } \\
\text { Earth-System Simulator, } \\
\text { version } 1.3\end{array}$ & 21 & 0.37 & 4.0 & $4.5 \pm 1.9$ & & \\
\hline BCC-CSM1.1 & $\begin{array}{l}\text { Beijing Climate Center, Climate System } \\
\text { Model, version } 1.1\end{array}$ & 30 & 7.9 & 4.8 & $5.8 \pm 0.84$ & 5.2 & $8.1 \pm 1.3$ \\
\hline CCSM4 & $\begin{array}{l}\text { Community Climate System Model, } \\
\text { version } 4\end{array}$ & 15 & 27 & 4.7 & $9.7 \pm 2.6$ & 2.8 & $14 \pm 8.7$ \\
\hline CNRM-CM5 & $\begin{array}{l}\text { Centre National de Recherches } \\
\text { Météorologiques Coupled Global } \\
\text { Climate Model, version } 5\end{array}$ & 5.9 & 21 & & & 2.0 & $7.7 \pm 3.5$ \\
\hline FGOALS-s2 & $\begin{array}{l}\text { Flexible Global Ocean-Atmosphere- } \\
\text { Land System Model, second spectral } \\
\text { version }\end{array}$ & 25 & 29 & 0.18 & $6.6 \pm 3.2$ & & \\
\hline GFDL CM3 & $\begin{array}{l}\text { Geophysical Fluid Dynamics Laboratory } \\
\text { Climate Model, version } 3\end{array}$ & 21 & 30 & 2.5 & $9.4 \pm 5.5$ & 2.8 & $13 \pm 7.6$ \\
\hline IPSL-CM5A-LR & $\begin{array}{l}\text { L'Institut Pierre-Simon Laplace Coupled } \\
\text { Model, version 5A, low resolution }\end{array}$ & 4.9 & 17 & 2.7 & $12 \pm 2.8$ & 2.1 & $21 \pm 4.2$ \\
\hline IPSL-CM5A-MR & $\begin{array}{l}\text { L'Institut Pierre-Simon Laplace Coupled } \\
\text { Model, version 5A, mid resolution }\end{array}$ & 0.96 & 13 & 2.1 & $12 \pm 1.8$ & & \\
\hline MIROC5 & $\begin{array}{l}\text { Model for Interdisciplinary Research on } \\
\text { Climate, version } 5\end{array}$ & 6.8 & 11 & -0.16 & $4.8 \pm 2.6$ & 0.77 & $8.0 \pm 3.2$ \\
\hline MRI-CGCM3 & $\begin{array}{l}\text { Meteorological Research Institute } \\
\text { Coupled Atmosphere-Ocean General } \\
\text { Circulation Model, version } 3\end{array}$ & 20 & 31 & 5.2 & $16 \pm 3.1$ & & \\
\hline NorESM1-M & $\begin{array}{l}\text { Norwegian Earth System Model, } \\
\text { version } 1 \text { (intermediate resolution) }\end{array}$ & 14 & 25 & 3.7 & $4.1 \pm 2.2$ & 3.7 & $9.0 \pm 5.3$ \\
\hline
\end{tabular}

* Not consistent when rain-rate response criterion is applied at the 99.9th percentile. 
we might take that as an indication that those models were closer to reality and more heavily weight their response to global warming. The companion paper, Pendergrass and Hartmann (2014b), focuses on the response to $\mathrm{CO}_{2}$ increase in models. One of the findings there is that some models have an extreme mode, which is an increase in rain rate at the highest percentiles of the distribution, while other models' responses are closely fit by the shift plus increase.

A challenge with this approach is that the two observational datasets disagree about many aspects of the response to ENSO. They disagree about the sign of the total change in rainfall. They disagree about whether the heaviest events should increase at rates greater (TRMM) or less (GPCP) than the shift-plus-increase prediction. However, they do agree that the magnitude of the shift mode is $14 \% \mathrm{~K}^{-1}$. They put a wide margin on the magnitude of the increase at the 99.99th percentile, from $-3 \%$ to $21 \% \mathrm{~K}^{-1}$ (the bottom of the GPCP range through to the high end of TRMM). We use two measures to sort the models: first, the 99.99th-percentile rain-rate response within the error bounds of either observational dataset (from $-2 \%$ to $21 \% \mathrm{~K}^{-1}$, a wide range of responses) and, second, a shift within one standard deviation $\left(6.5 \% \mathrm{~K}^{-1}\right)$ of the observational datasets $\left(8 \%-20 \% \mathrm{~K}^{-1}\right)$. The range of acceptable model responses is quite wide, but half of models do not fall within it. Two more models are inconsistent when the rain-rate response criterion is applied at the 99.9th, rather than the 99.99th, percentile. Table 2 lists the models that do and do not meet the criteria for consistency. Only models that also participated in the RCP8.5 or $\mathrm{CO}_{2}$-increase experiments are shown.

Models that are consistent with observations according to this criterion have increases in 99.99th-percentile rain rate for RCP8.5 or $\mathrm{CO}_{2}$-doubling experiments that are at most $9.0 \% \mathrm{~K}^{-1}$. Furthermore, in Pendergrass and Hartmann (2014b) we show that one consistent model (MPI-ESM-LR) has a large initial convective fraction while one inconsistent model (IPSL-CM5A-LR) has a small initial convective fraction. Models with large increases in extreme precipitation participating in the AMIP experiment are inconsistent with observations according to the criteria used here.

\section{Conclusions}

We have considered the rain amount and rain frequency distributions of daily precipitation data in CMIP5 models and in GPCP 1DD and TRMM 3B42 version 7 observational datasets and their changes in response to warm and cold phases of ENSO. CMIP5 models do a tolerable job of simulating the global distribution of rain amount by rain rate when compared to the GPCP 1DD observational dataset. The models produce a higher frequency of rain falling at light rain rates compared to observations, but the rain amount contributed at these light rates is small.

We introduce two modes of coherent change of the rain amount distribution: an increase in rain amount at all rain rates (the increase mode) and a shift of the rain amount distribution to higher rain rates (the shift mode). The increase changes total rainfall, while the shift does not. The degree of shift is expressed as a percentage change in rain rate, representing a movement of the rain amount distribution along an axis of the log of rain rate. The increase is expressed as a percentage change in rain amount at all rain rates.

We fit the shift and increase modes of the rain amount distribution to the modeled and observed response to warm and cold ENSO phases. Observational datasets disagree with each other about the change in mean rainfall over ocean in response to ENSO phases. Nonetheless, the shift plus increase fits much of the change in rain amount reasonably, reinforcing our confidence in the framework. Despite disagreement about total rain in the observational datasets, AMIP model simulations and both observational datasets produce a similar shift, between $14 \%$ and $15 \%$ $\mathrm{K}^{-1}$ during ENSO events. Models and observations agree on the differences between land and ocean responses to ENSO events. The response of the rain frequency as a function of rain rate and extreme rain rate as a function of percentile are also included in the framework.

Acknowledgments. CMIP5 modeling groups generously shared their simulations, and the resulting data were distributed by PCMDI. GPCP 1DD and TRMM 3B42 v7 groups generously made their data available. NOAA merged air land and SST anomalies data were provided by the NOAA/OAR/ESRL/PSD, Boulder, Colorado, from their website (http://www.esrl.noaa.gov/ psd/). Dargan Frierson participated in helpful discussions, and Kevin Trenberth and three anonymous reviewers provided helpful feedback. This work was funded by NSF under Grant AGS-0960497.

\section{APPENDIX}

\section{Rain Amount and Rain Frequency Distribution Calculations}

We calculate the distribution of rain amount $p$ and rain frequency $f$ for each dataset, using daily rain accumulation $r$ from model output or gridded observations. The $R_{i}^{l}$ and $R_{i}^{r}$ are left and right bin edges, and $R_{i}^{c}=\left(R_{i}^{l}+R_{i}^{r}\right) / 2$ is bin centers, which we use in transforming the distribution, 


$$
\begin{aligned}
p_{i}\left(R_{i}^{c}\right) & =\frac{1}{\Delta \ln R} \int_{\ln R_{i}^{l}}^{\ln R_{i}^{r}} p(\ln r) d \ln r \\
& =\frac{1}{\Delta \ln R} \sum_{\text {gridpts }} r\left(R_{i}^{l}<r<R_{i}^{r}\right) \frac{A_{\text {gridpt }}}{A_{\text {total }}} \\
f_{i}\left(R_{i}^{c}\right) & =\frac{1}{\Delta \ln R} \int_{\ln R_{i}^{l}}^{\ln R_{i}^{r}} f(\ln r) d \ln r \\
& =\frac{1}{\Delta \ln R} \sum_{\text {gridpts }} \frac{N_{d}\left(R_{i}^{l}<r<R_{i}^{r}\right)}{\Sigma N_{d}} \frac{A_{\text {gridpt }}}{A_{\text {total }}}, \quad \text { and } \\
F_{d} & =\frac{1}{\Sigma N_{d}} \sum_{\text {gridpts }} N_{d}(r=0) \frac{A_{\text {gridpt }}}{A_{\text {total }}}
\end{aligned}
$$

where $A$ represents areas of each grid point and the total area and $N_{d}$ is the number of days. The distributions are calculated a bin width $\Delta \ln R=$ $\left(R_{i+1}-R_{i}\right) / R_{i}=7.67 \%$, which gives reasonable sampling across the distribution.

\section{REFERENCES}

Allan, R. P., and B. J. Soden, 2008: Atmospheric warming and the amplification of precipitation extremes. Science, 321, 14811484, doi:10.1126/science.1160787.

, C. Liu, M. Zahn, D. A. Lavers, E. Koukouvagias, and A. Bodas-Salcedo, 2013: Physically consistent responses of the global atmospheric hydrological cycle in models and observations. Surv. Geophys., 35, 533-552, doi:10.1007/ s10712-012-9213-Z.

Allen, M. R., and W. J. Ingram, 2002: Constraints on future changes in climate and the hydrologic cycle. Nature, 419, 224-232, doi:10.1038/nature01092.

Chen, C.-T., and T. Knutson, 2008: On the verification and comparison of extreme rainfall indices from climate models. J. Climate, 21, 1605-1621, doi:10.1175/2007JCLI1494.1.

Chou, C., C.-A. Chen, P.-H. Tan, and K. T. Chen, 2012: Mechanisms for global warming impacts on precipitation frequency and intensity. J. Climate, 25, 3291-3306, doi:10.1175/ JCLI-D-11-00239.1.

Huffman, G. J., R. F. Adler, M. M. Morrissey, D. T. Bolvin, S. Curtis, R. Joyce, B. McGavock, and J. Susskind, 2001: Global precipitation at one-degree daily resolution from multisatellite observations. J. Hydrometeor., 2, 36-50, doi:10.1175/1525-7541(2001)002<0036:GPAODD>2.0.CO;2.

— , and Coauthors, 2007: The TRMM Multisatellite Precipitation Analysis (TMPA): Quasi-global, multiyear, combined-sensor precipitation estimates at fine scales. J. Hydrometeor., 8, 38 55, doi:10.1175/JHM560.1.

Jones, P. D., D. H. Lister, T. J. Osborn, C. Harpham, M. Salmon, and C. P. Morice, 2012: Hemispheric and large-scale landsurface air temperature variations: An extensive revision and an update to 2010. J. Geophys. Res., 117, D05127, doi:10.1029/ 2011JD017139.

Jones, P. W., 1999: First-and second-order conservative remapping schemes for grids in spherical coordinates. Mon. Wea. Rev.,
127, 2204-2210, doi:10.1175/1520-0493(1999)127<2204: FASOCR $>2.0 . C O ; 2$.

Klein Tank, A. M. G., F. W. Zwiers, and X. Zhang, 2009: Guidelines on analysis of extremes in a changing climate in support of informed decisions for adaptation. World Climate Data and Monitoring Programme Rep. 72 and WMO Tech. Doc. 1500, $56 \mathrm{pp}$.

Kopparla, P., E. Fischer, C. Hannay, and R. Knutti, 2013: Improved simulation of extreme precipitation in a high resolution atmosphere model. Geophys. Res. Lett., 40, 5803-5808, doi:10.1002/2013GL057866.

Lau, W. K.-M., H.-T. Wu, and K.-M. Kim, 2013: A canonical response of precipitation characteristics to global warming from CMIP5 models. Geophys. Res. Lett., 40, 3163-3169, doi:10.1002/grl.50420.

Liu, C., and R. P. Allan, 2012: Multisatellite observed responses of precipitation and its extremes to interannual climate variability. J. Geophys. Res., 117, D03101, doi:10.1029/ 2011JD016568.

—_, - _ and G. J. Huffman, 2012: Co-variation of temperature and precipitation in CMIP5 models and satellite observations. Geophys. Res. Lett., 39, L13803, doi:10.1029/ 2012 GL052093.

Masson, D., and R. Knutti, 2011: Climate model genealogy. Geophys. Res. Lett., 38, L08703, doi:10.1029/2011GL046864.

Mauritsen, T., and Coauthors, 2012: Tuning the climate of a global model. J. Adv. Model. Earth Syst., 4, M00A01, doi:10.1029/ 2012MS000154.

O'Gorman, P. A., 2012: Sensitivity of tropical precipitation extremes to climate change. Nat. Geosci., 5, 697-700, doi:10.1038/ngeo1568.

— , and T. Schneider, 2009: The physical basis for increases in precipitation extremes in simulations of 21st-century climate change. Proc. Natl. Acad. Sci. USA, 106, 14773-14777, doi:10.1073/pnas.0907610106.

Pall, P., M. Allen, and D. Stone, 2007: Testing the ClausiusClapeyron constraint on changes in extreme precipitation under $\mathrm{CO}_{2}$ warming. Climate Dyn., 28, 351-363, doi:10.1007/ s00382-006-0180-2.

Pendergrass, A., 2013: The atmospheric energy constraint on precipitation change. Ph.D. dissertation, University of Washington, $134 \mathrm{pp}$.

_ , and D. Hartmann, 2014a: The atmospheric energy constraint on global-mean precipitation change. J. Climate, 27, 757-768, doi:10.1175/JCLI-D-13-00163.1.

$\longrightarrow$, and — 2014b: Changes in the distribution of rain frequency and intensity in response to warming. J. Climate, 27, 8372-8383, doi:10.1175/JCLI-D-14-00183.1.

Pennell, C., and T. Reichler, 2011: On the effective number of climate models. J. Climate, 24, 2358-2367, doi:10.1175/2010JCLI3814.1.

Stephens, G. L., and Coauthors, 2010: Dreary state of precipitation in global models. J. Geophys. Res., 115, D24211, doi:10.1029/2010JD014532.

— , and Coauthors, 2012: An update on Earth's energy balance in light of the latest global observations. Nat. Geosci., 5, 691-696, doi:10.1038/ngeo1580.

Su, H., and J. D. Neelin, 2003: The scatter in tropical average precipitation anomalies. J. Climate, 16, 3966-3977, doi:10.1175/1520-0442(2003)016<3966:TSITAP>2.0.CO;2.

Sun, Y., S. Solomon, A. Dai, and R. W. Portmann, 2006: How often does it rain? J. Climate, 19, 916-934, doi:10.1175/JCLI3672.1. ,,,-- and -2007 : How often will it rain? J. Climate, 20, 4801-4818, doi:10.1175/JCLI4263.1. 
Taylor, K. E., R. J. Stouffer, and G. A. Meehl, 2012: An overview of CMIP5 and the experiment design. Bull. Amer. Meteor. Soc., 93, 485-498, doi:10.1175/BAMS-D-11-00094.1.

Trenberth, K. E., 1997: The definition of El Niño. Bull. Amer. Meteor. Soc., 78, 2771-2777, doi:10.1175/1520-0477(1997)078<2771: TDOENO $>2.0 . \mathrm{CO} ; 2$.

, 1999: Conceptual framework for changes of extremes of the hydrological cycle with climate change. Climatic Change, 42, 327-339, doi:10.1023/A:1005488920935.
- 2011: Changes in precipitation with climate change. Climate Res., 47, 123-138, doi:10.3354/cr00953.

—, A. Dai, R. M. Rasmussen, and D. B. Parsons, 2003: The changing character of precipitation. Bull. Amer. Meteor. Soc., 84, 1205-1217, doi:10.1175/BAMS-84-9-1205.

Watterson, I., and M. Dix, 2003: Simulated changes due to global warming in daily precipitation means and extremes and their interpretation using the gamma distribution. J. Geophys. Res., 108, 4379, doi:10.1029/2002JD002928. 